\title{
Molecular Detection and Identification of Fungal Pathogens
}

\author{
KATRIEN LAGROU, JOHAN MAERTENS, MARIE PIERRE HAYETTE
}

Fungi are a diverse group of eukaryotic organisms, most of which are found as saprophytes in soil and on decomposing organic material. Of the more than 100,000 fungal species, less than 500 have been implicated in human disease. Most fungi are opportunistic pathogens that cause only disease in (severely) immunocompromised patients. Many fungal diseases have a worldwide distribution, but some are restricted to specific geographical regions (e.g. endemic mycoses). Fungi cause a broad spectrum of diseases, ranging from superficial mycoses (infection of skin, hair, nails and/or mucosal membranes), and allergic diseases to lifethreatening invasive diseases. Most dermatophytes are not able to survive as free-living saprophytes and are obligate pathogens of animals and humans causing contagious infections. Millions of individuals worldwide are affected by superficial mycoses, mainly dermatophytoses and candidiasis $(1,2)$. An increase of invasive infections is seen during the last decades due to the ever increasing size of the population at risk for these infections (3) as well as the availability of better diagnostics.

The need for fast and accurate laboratory diagnosis is obvious for life-threatening invasive diseases but also for the diagnosis of dermatophytoses where a rapid and precise diagnostic test is needed to guide an optimal treatment (4). The isolation of a fungus from a clinical sample does not necessarily imply that the patient is suffering from fungal disease, given the ubiquitous nature of fungi. In addition, some of them are present in the human microbial flora. Thus differentiating contamination or colonization from infection is of great importance. Due to the varied and non-specific clinical signs of a fungal infection and the limited sensitivity of conventional diagnostic assays (microscopy and culture), research has been directed to the identification and detection of biomarkers (mainly antigens and nucleic acids) 
for fungal infections during the last two decades. The huge diversity of fungal pathogens complicates a correct identification of the species involved. The limitations of the identification only based on phenotypical methods are becoming more and more clear through the application of molecular techniques.

Molecular tests are not widely implemented yet in clinical laboratories for the diagnosis of fungal infections although PCR-based diagnostics is a fast growing segment in this domain. Two main applications for the use of molecular tests in the microbiology (mycology) laboratory will be discussed in this chapter, namely the detection (and identification) of fungal pathogens directly in clinical samples and the identification of fungal isolates cultured from clinical samples.

\section{MOLECULAR DETECTION OF FUNGAL PATHOGENS DIRECTLY IN CLINCAL}

\section{SAMPLES}

First we will discuss some general issues to be considered for the development of molecular fungal detection tests.

Molecular techniques can be applied for the detection and identification of virtually any fungus involved in human disease in many different sample types. In this section, we will discuss the role of molecular tests optimized for the detection of a broad range of fungi (called 'panfungal' tests). Next, we will discuss specific tests developed for the diagnosis of invasive aspergillosis (IA), invasive candidiasis (IC) and Pneumocystis jirovecii pneumonia (PCP) (or fungus-specific tests). For guidelines regarding the use of molecular tests for the diagnosis of mucormycosis, we refer to the recent ESCMID guidelines (5).

\section{General issues for the development of molecular tests for the detection of fungi}


Since the 1990s many studies about molecular diagnostics in the field of medical mycology have been published but results were often difficult to compare due to variations in testing parameters, differences in the definition of invasive fungal disease, and the amount and quality of technical information and data provided. In 2009 guidelines for Minimum Information for Publication of Quantitative Real-Time PCR experiments (MIQE) were published (6) to ensure the quality of real-time PCR evaluation manuscripts.

A characteristic feature of fungal cells is the presence of a rigid cell wall consisting mainly of polysaccharides (glucan, mannan), chitin and glycoproteins. Hence, efficient extraction of fungal DNA is difficult and appears to be the rate-limiting step for the development of a fungal molecular detection assay. Because the fungal load in clinical samples (e.g. blood or broncho-alveolar lavage (BAL) samples) from patients with invasive mycosis is usually low and often near to the detection limit of the most sensitive molecular detection techniques currently available, efficient extraction of fungal DNA is essential (7). Multicopy targets such as the rRNA gene targets (18S, 28S, and ITS regions) are preferred to enhance performance and sensitivity. Of course, obtaining sufficient fungal DNA is less critical for the development of a fungal identification test performed on clinical isolates.

The ubiquitous nature of fungi is another complicating feature, since it poses a high risk of contamination on several levels, i.e. during the sampling process, during the extraction phase but also during the PCR reaction due to fungal-DNA contaminated reagents such as enzyme preparations. One should ensure that only tested fungal-DNA free reagents are used for DNA extraction and PCR setup. Inclusion of (a) control sample(s) to detect contamination is mandatory in each test run.

Different procedures (percutaneous, bronchoscopic, via open surgery or via video-assisted thorascopic surgery) to take biopsies for molecular tissue diagnosis of invasive fungal infections have been reviewed by C. Mrazek and C. Lass-Flörl (8). 
PCR-based assays are currently the most common molecular-based approach for the diagnosis of fungal infections and most PCR amplification systems perform with excellent efficiency. Agarose-gel electrophoresis is not recommended for fungal detection (as it is for other microorganisms) because of the lower sensitivity compared to probe-based detection systems and the relatively low specificity. Due to contamination risk, nested PCR formats are not recommended anymore in this setting. The introduction of real-time amplification PCR greatly advanced the field of molecular microbiology in general and of medical mycology in particular. Real-time PCR assays with species-specific detection probes have eliminated the need of post-PCR amplicons handling, minimizing the risk of laboratory contamination. In addition, results are quantifiable. Furthermore, identification of the fungus can also be realized by amplicon sequencing (9). Microarray technology can be used as an alternative for amplicon characterization (10). However, the preferred method depends also on the extraction and amplification platforms available to the user. Most molecular tests in the field of mycology amplify fungal DNA. Few publications report results of RNA detection techniques such as the Nucleic Acid Sequence-Based Amplification (NASBA) technique (11, 12).

\section{Detection of broad range of fungi}

In particular clinical settings and diagnostic-based strategies, assays may be designed to detect a broad range of fungal pathogens. Such assay can be implemented to screen patients at high risk for invasive fungal disease. In addition, they can be used on sterile-site samples (e.g. blood, cerebral fluids, tissue biopsies) in which fungal elements were detected by microscopy/histology but remained culture negative.

Detection of a broad range of fungi can be achieved by a multiplex format with primers targeting a set of different species or by the design of PCR primers that target conserved regions of the fungal DNA ('panfungal primers'). Species identification can be achieved by 
the use of specific labeled probes, hybridization to a DNA microarray or sequencing of the PCR product in order to guide further diagnostic testing or antifungal therapy. The use of specific probes to further characterize the amplification product is preferred over the use of intercalation dyes, such as SYBR Green and melting curve analysis (13). When these broadrange assays are used on non-sterile site samples (such as bronchial aspirates or BAL fluids), the detection of clinically non-relevant saprophytes (such as Penicillium species) may represent a problem. Of note, the use of 'panfungal primers' may be limited by the fact that greater target diversity is associated with reduced sensitivity; primers that were optimized to detected specific pathogens tend to have greater sensitivity (14). As such, when a pan-fungal PCR is used to exclude a fungal infection, a negative test result may need to be followed by more specific PCRs designed to target the most prevalent fungal pathogens (depending on the clinical setting, e.g. an Aspergillus PCR) to improve the sensitivity of the detection and avoid the need for post PCR steps. Another limitation is the difficulty to detect the different pathogens involved in case of a polyfungal infection. Often only the fungus with the highest load in the sample will be picked up. This is of clinically relevance as polyfungal infections may be more prevalent that generally estimated. In patients with invasive mucormycosis for instance, surveillance studies revealed that co-infections with Aspergilli is a common phenomenon $(15,16)$. A pan-fungal design also harbors the risk of hybridization with any eukaryotic DNA and thus also human DNA which is often present in huge amounts in human samples (17).

Several authors reported excellent performance of pan-fungal home-brew assays (performed on blood or tissue samples) for the diagnosis of invasive fungal diseases (18-21). In the Spanish Mycology Reference Laboratory following algorithm is applied for tissue biopsy specimens that are culture negative. A specific PCR test is performed in case of a clear clinical, epidemiological, or histopathological suspicion of a specific fungal disease such as 
aspergillosis, mucormycosis, scedosporiosis, fusariosis or histoplasmosis. When no informative data about the fungal pathogen involved is available, a panfungal assay is performed. Also, when the initial specific PCR assay results are negative, a panfungal assay is performed (18). With this approach, the lab was able to identify the species implicated in all 132 patients from whom they received 151 biopsy samples during the period 2006-2013. Four cases of mixed infections were detected, they all involved Aspergillus spp. mixed with Candida spp. or species of Mucorales.

Commercially available 'broad-spectrum PCR tests' were mainly designed for the detection and identification of bacterial and fungal pathogens associated with sepsis. The LightCycler ${ }^{\circledR}$ SeptiFast Test MGRADE (Roche Diagnostics GmbH, Mannheim, Germany) was the first CE cleared PCR kit for the rapid detection and identification of 25 common bloodstream infection pathogens including five Candida spp. and Aspergillus fumigatus. The assay is based on real-time PCR targeting species-specific ITS regions. Several evaluation studies were conducted but the total number of patients included with a fungal bloodstream infection remains limited (22). The Vyoo ${ }^{\circledR}$ test (Analytik Jena AG, Jena, Germany) is a multiplex PCR assay allowing the simultaneous amplification and detection of 34 bacterial and 7 fungal species (Aspergillus fumigatus, Candida albicans, Candida dubliniensis, Candida glabrata, Candida krusei, Candida parapsilosis, Candida. tropicalis), as well as 5 antibiotic resistant genes. The procedure contains a mechanical lysis step for whole blood (up to $5 \mathrm{~mL}$ ), automated total DNA extraction and a patented pathogen DNA enrichment technology. The SepsiTest ${ }^{\mathrm{TM}}$ from Molzym GmbH \& Co. KG (Bremen, Germany) is a CEIVD kit that uses broad-range primers that bind to conserved regions of rRNA genes for the detection of a broad range of bacteria and fungi in whole blood. Sequencing of the amplicons allows direct identification of the pathogen detected. The RenDx Fungiplex assay (RENISHAW Diagnostics Limited, Glasgow, United Kingdom), based on multiplex PCR and 
detection by surface enhanced Raman scattering, was developed for the detection of the most common fungal pathogens. The test result is reported as Candida spp (includes C. albicans, C. parapsilosis, C. tropicalis, C. guilliermondii, C. lusitaniae, C. dubliniensis), C. krusei, C. glabrata, Aspergillus species (includes A. fumigatus, A. flavus, A. niger) or A. terreus.

Promising clinical performance was demonstrated in a recent retrospective clinical evaluation (23). These assays have the potential to provide a rapid (depending on the availably during weekends and nights) detection of fungal pathogens causing invasive fungal infections but prospective clinical evaluations are needed to better define their added value to blood cultures and other biomarkers such as Aspergillus antigen (galactomannan, GM) and $\beta$-D-glucan (BDG). As these molecular assays cannot replace blood cultures and are more expensive, it is also important to determine for which patient groups the implementation of a molecular sepsis test can be cost effective.

\section{Diagnosis of invasive candidiasis}

The current gold standard for the diagnosis of IC is blood culture and cultures from sterile sites but the slow turnaround time and poor sensitivity are important limitations. In a Danish surveillance study, time to blood culture positivity for two blood culture systems (BacT/Alert and BACTEC) was similar but species dependent. Blood cultures from episodes due to $C$. tropicalis or C. krusei were positive after a median incubation time of 1 day, whereas blood cultures from fungemia episodes due to C. albicans, C. glabrata, or C. parapsilosis were positive after a median incubation time of 3 days, with $25 \%$ of the episodes due to $C$. glabrata being positive on day 4 or later (24). In patients with autopsy-proven hepatosplenic candidiasis, pre-mortem positivity rates of less than $50 \%$ are reported for blood cultures $(25$, 26). 
A commercial non-nucleic acid amplification method, the Yeast Traffic Light ${ }^{\circledR}$ PNA FISH $^{\circledR}$ (AdvanDx), was developed for the identification of Candida albicans/Candida parapsilosis, Candida tropicalis and Candida glabrata/Candida krusei in positive blood cultures. The assay is based on peptide nucleic acid (PNA)-FISH technology and uses nucleic acid probes targeting the 26S $r$ RNA region. The test is FDA and CE-cleared and clinical validation of this assay demonstrated high sensitivity and specificity (27). Only a limited number of Candida species can thus be identified which is certainly a limitation compared to matrix-assisted laser desorption ionization-time of flight mass spectrometry (Maldi-Tof MS) which is promising non-molecular technique for a rapid identification of yeasts in positive blood cultures (see below).

The performance of culture and non-culture diagnostics for invasive candidiasis with a focus on the so-called 'missing $50 \%$, i.e. patients with invasive candidiasis who are not diagnosed by blood cultures, was recently reviewed by Clancy and Nguyen (28). Guidelines for the diagnosis of invasive candidiasis have been developed by ESCMID (29). Molecular assays are potentially attractive because of their high sensitivity when targeting multicopy genes, their capacity for rapid speciation and the ability to quantitate the fungal burden. A challenging aspect is the low burden of Candida cells during bloodstream infections. Less than 10 colony forming unit $(\mathrm{CFU}) / \mathrm{mL}$ (in $25 \%$ of patients even less than $1 \mathrm{CFU} / \mathrm{mL}$ ) are circulating in the bloodstream (30). Also the intermittent nature of candidemia due to hepatic clearance of fungal cells and/or the periodic release of cells from deep organ sites into the circulation plays a role (31). Compared to culture, PCR detects both viable and dead Candida cells including freely circulating DNA that may be present after organisms are eliminated from the circulation (30). In a rabbit model of disseminated candidiasis a steady increase of Candida DNA levels occurred in plasma as disease progressed. Phagocytic cells may play an 
active role in increasing this DNA release over time. Plasma is thus a suitable blood fraction for invasive candidiasis assays (31).

A comparison between PCR validation studies is complicated because of variations in testing parameters, the single-institution design of these studies and differences in the definition of disease and control population. Avni et al. conducted a systematic review and meta-analysis to assess the diagnostic accuracy of PCR-based methods to detect Candida spp. directly in blood samples (25). A total of 54 studies were included with 4,694 patients, 963 of whom had proven/probable or possible invasive candidiasis. Perfect (100\%) sensitivity and specificity for PCR in whole-blood samples was calculated when the evaluation was limited to cases with candidemia and healthy controls. PCR positivity rates among patients with proven or probable invasive candidiasis were $85 \%$, while blood cultures were positive for $38 \%$ of cases. The use of whole-blood samples, rRNA, or P450 gene targets and a PCR detection limit of $\leq$ $10 \mathrm{CFU} / \mathrm{ml}$ were associated with improved test performance. M. Nguyen et al. compared the performance of a validated Candida real-time PCR and the Fungitell ${ }^{\circledR}$ BDG assay on blood samples with blood cultures from prospectively included patients with invasive candidiasis and hospitalized controls. In this study, PCR on plasma or sera was more sensitive than whole blood for diagnosing invasive candidiasis $(\mathrm{p}=0.008)$. PCR had a similar sensitivity as BDG detection for diagnosing candidemia but a higher sensitivity for diagnosing deep-seated candidiasis. The highest sensitivity $(98 \%)$ was achieved by combining blood cultures with PCR (32).

From a clinical point of view, a major unmet need is the diagnosis of blood culture negative, deep seated candidiasis. It will be important to include these patients in carefully designed diagnostic trials. It is expected that wide use of non-culture techniques will improve our understanding of invasive candidiasis and will lead to a knowledge that is less skewed towards the clinical entity with candidemia. 


\section{Diagnosis of invasive aspergillosis}

Contrary to invasive candidiasis, blood cultures are not useful for the diagnosis of IA, even not in case of disseminated disease. Most patients present with invasive pulmonary aspergillosis but the sensitivity of culture of respiratory samples is at best $60 \%$. Diagnosis of IA cannot be made on the basis of a positive laboratory test result only (except in case the fungus is detected in a sterile-site sample) but should be based on the integration of clinical, radiological and microbiological signs (33). GM and BDG detection are included in the revised criteria of the European Organization for Research and Treatment of Cancer (EORTC) for the definition of probable disease; this is not (yet) the case for molecular tests. The European Conference on Infections in Leukemia (ECIL) Laboratory Working Groups concluded that there is good evidence to support the use of GM detection in serum for the diagnosis of IA in adult leukemic patients and hematopoietic SCT recipients (AII grading) and moderate evidence for BDG detection in serum (BII grading). Detection of GM in bronchoalveolar lavage (BAL) fluid samples of patients at risk of invasive pulmonary aspergillosis was shown to have an excellent diagnostic accuracy $(34,35)$.

A major obstacle for the design of molecular assays for the diagnosis of IA is the very low fungal load in clinical specimens, especially in blood (certainly when compared to the millions of viruses that are detected in patients with viral diseases). During the last decades, numerous in-house developed assays with many different target sequences and PCR protocols have been published. The last 8 years, great efforts have been done to improve the standardization of these assays. The first multicenter study of PCR methods for the detection of Aspergillus and Candida species was conducted by the United Kingdom Fungal PCR

Consensus Group and can be considered as the initial attempt to achieve a consensus method (36). In 2006, the European Aspergillus PCR Initiative (EAPCRI; www.eapcri.eu), a working 
group supported by the International Society of Human and Animal Mycology (ISHAM) was founded. The aim was to put forward clear recommendations for the design of PCR-based techniques for the detection of Aspergillus DNA in clinical samples. To improve the analytical sensitivity of the detection of Aspergillus DNA in whole blood, the EAPCRI recommends the use of $\geq 3 \mathrm{ml}$ EDTA blood specimens, a red and white cell lysis step, bead beating to lyse the fungal elements, and elution volumes of less than $100 \mu \mathrm{l}(37)$. It is not yet fully understood how Aspergillus DNA circulates in the bloodstream, either associated with the fungal cell and/or as free DNA. As such, the optimal clinical specimen for PCR testing for IA is still subject of considerable debate. Serum is an attractive matrix because the extraction of free DNA is easy and permits fully automation on the same instruments as used for the extraction of bacterial and/or viral DNA. This matrix also allows the use of a single sample for GM, BDG and PCR analysis. In a multicenter comparison of serum and whole-blood specimens for detection of Aspergillus DNA in high-risk hematological patients, 803 samples from 47 cases (proven and probable IA) and 31 controls (without IA) were tested to determine the performance of whole-blood PCR, serum PCR, and serum GM testing. There was no significant difference between whole-blood and serum specimens for PCR-based diagnosis of IA. There was a trend for whole blood to be more sensitive ( $85 \%$ versus $79 \%)$ than serum, however false positivity was higher for whole blood specimens compared to serum. The best performance was obtained by combining different assays (GM and PCR) (38). In conclusion, there is no clear evidence that whole blood or serum is better for Aspergillus PCR and thus the selection of the sample type for DNA extraction may be guided by the technical platforms available at each individual center.

In a prospective multicenter study including 58 respiratory tract biopsy samples from patients with a proven invasive mold infection, the etiological diagnosis increased from $63 \%$ based on 
culture to $96 \%$ by the additional use of two seminested PCR assays (that target mitochondrial DNA of Aspergillus species and the 18S ribosomal DNA of Mucorales respectively)(39). Several commercially available real-time PCR tests for the detection of Aspergillus DNA have contributed to the standardization of PCR testing. The MycAssay ${ }^{\circledR}$ Aspergillus (Trinity Biotech, Ireland) employs molecular beacon technology targeting the 18SrRNA gene and is developed for the detection of DNA from 15 different Aspergillus spp. However, the assay cross-reacts with Penicillium species. This kit was launched together with the MycXtra ${ }^{\circledR}$ kit for the extraction of fungal DNA from respiratory samples and includes a bead beating step for the disruption of the fungal cell wall. Sensitivity and specificity of the PCR on BAL fluid from high risk patients with proven or probable IA ranged between $93.0-94.1 \%$ and $82.4 \%$ 98.6\% respectively $(40,41)$. Also other commercial PCR-based tests specifically designed for Aspergillus detection are available such as the Affigene ${ }^{\circledR}$ Aspergillus tracer kit which is CE labeled for analysis of whole blood, serum and plasma samples. With this kit, there is also cross reaction with Penicillium species and clinical validation is still lacking.

\section{Diagnosis of Pneumocystis jirovecii pneumonia (PCP)}

Pneumocystis jirovecii is a pathogen specific for humans which cannot be found in the environment. Immunocompetent individuals are the most important reservoir where the fungus lives at the surface of the alveolar cells. The best sample for the diagnosis of PCP is BAL fluid; the lowest load is found in specimens taken from the upper respiratory tract. The detection of cysts and/or trophic forms by staining is still considered the gold standard for the diagnosis of PCP but important limitations of this detection method are the suboptimal reproducibility due to the subjective interpretation, the need for highly trained lab technicians, the labor intensity of the procedure and the lack of sensitivity in non-HIV immunocompromised patients due to the low burden of $P$. jirovecii. Because of these 
limitations PCR and more recently BDG are implemented progressively in clinical laboratories for the diagnosis of PCP. Several authors published on home-brew developed PCR methods with different targets which were evaluated in two meta-analyses. This evaluation revealed a high pooled sensitivity $(>98.3 \%)$ for PCP PCR performed on BAL fluid samples and a pooled specificity of $>88 \%(42,43)$. Because of the high sensitivity, a negative PCR test on BAL fluid may be used to rule out a PCP diagnosis. Quantitative PCR and the major surface glycoprotein gene target were associated with higher specificity(42). The MycAssay ${ }^{\mathrm{TM}}$ Pneumocystis kit (Trinity Biotech, Ireland) was the first commercial PCR assay and targets $P$. jirovecii mitochondrial large subunit DNA. Performance was evaluated in a multicenter trial of 110 patients (14 patients with PCP). PCR sensitivity, specificity, and positive and negative predictive values were $93 \%, 90 \%, 65 \%$ and $98 \%$ respectively (44). It is clear that the sensitivity of PCR detection tests for Pneumocystis is greater than of staining methods and that PCR tests may render positive results in patients that are colonized but not infected by Pneumocystis (45). Therefore, quantitation of the fungal load is of utmost importance for the interpretation of test results and the distinction between colonization and infection. Consequently real-time quantitative PCR is the preferred PCR method for PCP testing. Unfortunately there is no international standard available. Quantitative results are expressed in different ways, i.e. as copy numbers per volume unit, as numbers of microorganisms (for example trophic form equivalent) per volume unit or as the cycle threshold which is defined as the number of cycles required for the fluorescent signal to cross the threshold. Botterel F et al. (46) evaluated the clinical significance of quantifying Pneumocystis jirovecii DNA by real-time PCR in BAL fluid from immunocompromised patients. With immunofluorescence as the gold standard, PCR assay sensitivity was $100 \%$ applying a threshold $\geq 2.6 \log (10)$ copies $/ \mu 1$ and specificity reached $100 \%$ when the threshold was raised to $\geq 4 \log (10)$ copies/ $\mu$ l. The relevant threshold remains to be determined and may 
vary according to the underlying disease of the patient. Combination of BAL PCR and serum

BDG results may aid in the differentiation between PCP and colonization as suggested by

Damiani et al. (47). In future there may also be a role for the detection of circulating

Pneumocystis DNA in blood samples, but this needs further evaluation (48).

\section{MOLECULAR IDENTIFICATION OF FUNGAL PATHOGENS}

In severely immunocompromised patients, almost every fungal species can induce invasive mycosis $(49,50)$. Therefore in this setting correct identification of a fungal isolate to the species level is mandatory to appreciate the potential pathogenic role of the fungus, to aid in the interpretation of the in vitro antifungal susceptibility testing results and for epidemiological purposes. Also for isolates cultured from patients with dermatophytosis, it is interesting to know the correct identification of the dermatophyte involved to apply the optimal treatment, optimal duration of treatment and appropriate prophylactic measures to avoid reinfection or transmission of the infection to contacts (51). This applies for example to species responsible for tinea capitis such as Microsporum canis and Microsporum audouinii. These 2 species are classified in the same teleomorph complex and cannot always be distinguished phenotypically.

On the other hand, in the clinical microbiology laboratory, not all fungal isolates should be identified to the species level, since many will not be involved in disease. The clinical context and sample site should always be considered and help to orientate the mycologist in face of the macroscopical or microscopical aspects of the colony. Actually, the clinical need to identify complexes to the species level such as for Aspergillus of Fusarium complexes or within the Mucorales is not evident.

Since 2009, matrix-assisted laser desorption ionization-time of flight mass spectrometry (Maldi-Tof MS) has revolutionized the way to work in many laboratories because this method 
can identify bacteria and fungi to the species level in only a few minutes and with a high reliability, replacing the conventional methods. Nevertheless when Maldi-Tof MS is failing or to ascertain a correct identification of a fungal species, the gold standard method is still DNA sequencing targeting fungal ribosomal genes.

\section{MALDI-TOF MS}

Maldi-tof MS is a soft ionization technique used in mass spectrometry to analyze biomolecules (DNA, proteins, peptides and sugars) and large organic molecules. The most popular application in clinical microbiology is the identification of bacteria and fungi through their protein composition $(52,53)$. The principle of this technique is to mix the sample/colony with a matrix consisting of crystallized molecules and to submit the mixture to a laser beam in an ionization chamber under vacuum. The matrix is desorbed and ionized by addition of a proton that is further transferred to the peptides and proteins released by the laser firing. The ionized molecules are accelerated in an electric field and directed to the analyzer which classifies them according to the mass to charge ratio. The mass spectra which are generated are compared to a database containing reference spectra giving identifications associated with a rating score expressed as a $\log$ score from 0 to 3 or as percentage of agreement with reference spectra. Currently, two different systems are commercialized for microbiology applications: the Bruker Daltonics system (Microflex LT) with his database Biotyper (Bruker, Bremen, Germany) and the Shimadzu AXIMA system (Shimadzu-Biotech corp., Kyoto, Japan) using the database of SARAMIS (AnagnosTec, Postdam, Germany) or Andromas (Andromas, Paris, France)(54). Numerous publications confirm the performance of the systems particularly when applied to yeast identification with up to $98.8 \%$ of accuracy (54-58) and generally good agreement between both Maldi-tof MS different systems (59). However and in contrary to the algorithm used for bacteria (with the exception of 
mycobacteria), a lower cutoff score of 1.7 is usually used for the identification of yeasts in order to increase the sensitivity of the method (59-61). For yeasts identification, there is generally no need to perform protein extraction before analysis and identification can be directly performed on the colony. Furthermore, one advantage of the Bruker Biotyper over the Shimatzu system is the possibility to enrich the database for increasing identification accuracy $(58,61)$. This is particularly interesting for molds which are much more difficult to identify by Maldi-tof systems than yeasts. Indeed for filamentous fungi, both lowering the cut-off scores to 1.7 (62-64) and enrichment of the database are mandatory to obtain a correct identification $(60,65-67)$.

\section{Molecular sequencing methods}

\section{Nucleic acids extraction methods}

Extraction methods used for clinical samples can generally also be applied to fungal cultures but the DNA concentration can be increased using additive steps into the extraction protocol as for example freeze-thawing, a very powerful method to break fungal cell walls. Many protocols can be used in order to extract nucleic acids (NA) from fungal cultures from simple boiling for a rapid preparation of small amount of impure DNA to more elaborate and timeconsuming protocols. These latter generally use physical disruption of the fungal wall like bead-beating (with ceramic beads), freeze-thawing (68), high speed cell disruption (69), sonication (70), or chemical methods with heat-alkali treatment, or enzymatic digestion using lyticase and/or proteinase $\mathrm{K}(50,70,71)$. These methods are often included and/or combined into in-house protocols and are followed by a purification step performed manually (Qiagen columns) or on automates using magnetic beads as for example MagNAPure(Roche $\left.{ }^{\circledR}\right)$, Easymag (bioMerieux ${ }^{\circledR}$ ), and Maxwell16 LEV® (Promega) or using column-based kits (QiAamp DNA minikit ${ }^{\circledR}$, Qiagen) on a dedicated automate, Qiacube ${ }^{\circledR}($ Qiagen)(72). Some 
commercial kits are also available and provide entire protocols as for example the 'Ultra clean DNA isolation kit $^{\circledR}$ ' (MoBio Laboratories, USA) which allows extraction of high DNA concentrations as shown when it is applied to dermatophytes (68). Many other kits are available and applicable to fungal cultures: most of them are preceded by a pre-treatment including enzymatic digestion or bead-beating. In a recent comparison of 5 extraction methods (73), the highest DNA yield was obtained by using the ZR/fungal/bacterial DNA kit (Zymo Research, USA), YeastStar genomic DNA (Zymo Research), and QIAamp DNA Mini Kit (Qiagen) with bead-beating pre-treatment, a mandatory step to optimize the DNA extraction from fungal cells as demonstrated by Whyte L. et coll. (37).

Other approaches have been developed to minimize the length of the extraction protocols to less than one hour $(74,75)$. One of those is the Whatman FTA filter method developed by Borman and al. (76-78). This method is being used since many years for the sampling, extraction and storage of many other microorganisms like protozoa (79) or viruses (80). FTA technology is cheap and fast (about 15 minutes) and uses Whatman FTA filter matrices, that are fibrous cards pre-treated with chelators and denaturants that lyse and inactivate most of the microorganisms. These cards allow the extraction of as little as 10ng genomic DNA depending of the fungal concentration deposited on the cards.

\section{Targets for molecular sequencing}

Sequencing methods applied to fungi include different targets like genes encoding for proteins (actin, $\beta$-Tubulin, calmodulin, elongation factor $1 \alpha$ ), or for enzymes (chitin synthase, enolase, cytochrome b) or partial sequences of the ribosomal DNA (rDNA) gene complex. The advantages of rDNA over the other targets is their universal representation in fungi, their presence in multicopy genes, and the highly conserved sequences interspaced with highly variable regions allowing differentiation even between high related species. But none 
of the targets provides universal fungal differentiation and the targeted sequences have to be chosen based on background knowledge of the fungal targeted group. However, overall, the most common target used is the Internally Transcribed Spacer (ITS) region including ITS15,8S-ITS2, being recognized as the formal metabarcoding sequence $(17,81)$. The Clinical and Laboratory Standards Institute (CLSI) published a document in 2008 proposing a uniform approach to the molecular identification of fungi by use of broad-range DNA target using the ITS operon (82). In the document, guidelines for primer design, quality controls parameters for amplification and sequencing, measurement of sequence quality, and assessment of databases are provided. Balajee et al. propose an algorithm for the identification of filamentous fungi with no a priori knowledge (83). This algorithm classifies a fungus into a complex of species and the identification can always be completed further on using other molecular targets.

The rDNA gene complex of the fungal genome includes a sequence of subunits associated as follows:5'-18S/ITS1/5,8S/ITS2/28S/IGS1-5S-IGS2-3' (Figure 1) (84). The external transcribed spacers IGS1 and IGS2 are non-transcribed sequences and include the 5S rDNA gene which has a variable positioning and is not transcribed at the same time than the other rDNA genes. The entire rDNA gene complex is repeated many times along the fungal genome.

Regarding the transcribed spacer regions, only the ITS region including the ITS1-5,8S-ITS2 unit is interesting and is the most widely used for fungal species differentiation because of the high variability of the ITS sequences. The majority of the published data describe the use of the entire unit $(71,75,85)$ however ITS2 can also be used alone particularly if the DNA is potentially damaged. It has been recently shown that ITS2 is more suitable for species differentiation of fungi in comparison with the entire region or ITS1 alone (86). 
The size for the entire ITS region, ITS1 and ITS2 is about 600-700bp, 300bp and 400bp respectively depending of the fungal group concerned (87). The most commonly used primers have been developed by White TJ et al. (88): ITS1, ITS2, ITS3, ITS4 and by Gardes et al. (89), ITSF and ITS4B.The latter are more specific for fungi (ITS1F) or basidiomycetes (ITS4B) $(86,89)$ than those designed by White et al. (88). Primer ITS1F is usually combined with ITS2 to amplify the ITS1 region and ITS3 is generally combined with ITS4 to amplify the ITS2 region $(71,85,86,90,91)$. These primers have been largely used in mycology, however, other primers can also be used as for example ITS86F (ITS86 Forward) combined with ITS4 $(92,93)$ (Figure 2).

The 18S rDNAgene (corresponding to the small subunit or SSU) includes about $1800 \mathrm{bp}$ with both conserved and variable regions. This region has been used for species identification or as target in PCR-based protocols (94). However because of high sequence homology among fungal species, it is necessary to choose a long DNA fragment in order to allow adequate species differentiation (84). The $5.8 \mathrm{~S}$ is about $160 \mathrm{bp}$, is highly conserved but is not appropriate for species identification. This region is often used as binding site for primers (86, $95,96)$. The $28 \mathrm{SrDNA}$ gene or large subunit (LSU) is longer with about $3400 \mathrm{bp}$. It contains very conserved regions but also discrete domains (called "D" regions) ranging from D1 to D12 which alternate with more or less conserved regions. The D1/D2 regions contain the majority of variable sequences and are used for species differentiation $(75,85,97)$.

The Sanger-sequencing method is the most common technique used for DNA-sequencing. This technology is typically already in use for other applications in the clinical laboratory before implementation for identification of fungal pathogens. We refer to a recent review of Church (98)

\section{Pyrosequencing}


Pyrosequencing is another sequencing technique which allows a more detailed characterisation of the fungal community than the Sanger sequencing method. This technology is applied to the amplification of short-read DNA sequences and is based on the synthesis of the cDNA from PCR amplicons: if there is a complementary base, pyrophosphate is released. This signal is detected in real-time and gives the sequence of the DNA template. This method, however less popular than the Sanger method, has been successfully applied to the differentiation of Candida species (77, 99, 100), Aspergillus species (101) and for fungal identification targeting the ITS2 rRNA region (86). Pananusorn et al. were able to distinguish very related Candida species as in the C. paraspilosis complex by pyrosequencing of 40 nucleotides (100).

\section{Application of molecular identification methods to different fungal groups}

Yeasts

Candida and Cryptococcus. Molecular identification of the majority of the yeasts encountered in clinical microbiology targets usually the full ITS operon because even closelyrelated species such as Candida albicans/C. dubliniensis, C. inconspicua/C. norvegensis, $C$. parapsilosis/C. metapsilosis/C. orthopsilosis can be distinguished $(85,102)$. However, when it comes to differentiate Cryptococcus neoformans var. grubii from C. neoformans var. neoformans, the variability of the ITS operon is not sufficient and another target is recommendable as for example the rRNA intergenic spacer (IGS)(103).

\section{Molds}

Aspergillus. Following the European working group (104), ITS sequence can be used for differentiation to the species complex level such as for example A. fumigatus or A. flavus 
complex, while the differentiation to the species level into the sections, necessitates the amplification of other targets like $\beta$-tubulin, calmodulin, and rodlet A genes (83).

Fusarium. About 200 species are grouped into to Fusarium complexes and the differentiation to the species level needs the use of molecular sequencing tools. The ITS operon (105) and $\beta$ tubulin (106) have been successfully used as molecular targets to identify Fusarium species. However, the translating elongation factor-1alpha (TEF-1 $\alpha)$ provides a more detailed differentiation in phylogeny studies (106) and has been used in the last epidemiological European survey $(107,108)$.

Mucormycotina. Most of the isolates can be identified by using the ITS operon $(90,91)$. However, it has been demonstrated that some isolates are difficult to identify to the species level. In this case the D1/D2 region, actin gene, EF-1 $\alpha$ can be used as complementary target sequences (104).

Dermatophytes. Since 1980, the development of new molecular techniques (RFLP, sequencing, fingerprinting) allowed a better knowledge of the genetic diversity of the dermatophytes, and has participated to numerous reclassifications in this group $(104,109)$. The LSU as well as the full ITS operon have been successfully used as target in sequencing methods applied to dermatophytes identification whereas the SSU (18S rRNA region) is unable to correctly differentiate species. The majority of the primers combinations published in the literature has been reviewed by Cafarchia et al. (109). Briefly, PCR-based techniques have demonstrated that the discriminating power for dermatophytes identification is identical between the LSU and full ITS region $(110,111)$. For dermatophytes sequencing methods, many authors refer to Gräser et coll. (112) using the combination of two primers LR1 and SR6R with binding sites situated into the flanking $18 \mathrm{~S}$ and $28 \mathrm{~S}$ rDNA sequences of the ITS operon. These combination allows a good discrimination even for high-related species belonging to the same complex as for example Arthroderma benhamiae or Arthroderma 
vanbreuseghemii complex (112). The same group has proposed $(109,113)$ a new

classification for anthropophilic and zoophilic dermatophytes. There is a need to take into account the discriminating power of the technique used to distinguish for instance teleomorph complexes such as Arthroderma vanbreuseghemii from Arthroderma benhamiae complexes and if the name of the anamorph can be determined correctly. Currently, ignoring all the classification details or using an incomplete methodology, it is always preferable to refer the isolate as part of the teleomorph complex rather than to go to the species level to avoid misidentifications (113-115).

For those who prefer to use a commercially available kit, the Microseq D2 LSU rRNA Fungal sequencing kit (Applied Biosystems, USA) has been successfully applied to the determination of dermatophytes species using reference strains for sequence comparison $(111,115)$.

\section{Databases used for fungal molecular identification}

Different databases are used in mycology including GenBank (http://www.ncbi.nlm.nih.gov), CBS (http://www.cbs.knaw.nl/), European Molecular Biology Laboratory nucleotide sequence database (http://www.ebi.ac.uk/embl/) and the DNA Data Bank of Japan (http://www.ddbj.nig.ac.jp/). The most widely used database is GenBank, which contains a huge number of sequences, but these are combined with unedited and non-validated information, which may be updated and corrected only by the original submitter. Errors in fungal sequences within GenBank have been found to be as high as $20 \%$ (83). To overcome these problems, specific sequence databases for particular groups of fungi, based on quality-controlled sequences, have been created. Concerning the medical relevant fungi, two ITS databases are available through the CBS Fungal Biodiversity Centre (http://www.cbs.knaw.nl) and at the Westmead Millennium Institute, University of Sydney 
(curated database; http://www.mycologylab.org/biolomicsid.aspx)(83). As suggested by the same author, we also recommend creating a unique fungal database with high quality controlled sequence to gather all the mycological sequences data.

\section{CONCLUSIONS}

The diagnosis of fungal infections remains challenging due to the non-specific clinical signs and symptoms of these infections and the limitations of the currently available diagnostic tests. To improve our capability to diagnose these infections and to guide treatment, the value of molecular diagnostic methods in this field is explored extensively.

Numerous protocols for molecular diagnostics in mycology were published since the 1990's but their broad implementation was hampered due to the lack of standardization and clinical validation. Important steps forward were made toward the standardization of molecular testing in the fungal field by the publication of recommendations for the development and implementation of home-brew tests, the increasing availability of commercial tests and external quality control programs. As these molecular tests generally do not replace conventional tests and are expensive, it is important to demonstrate that these tests really impact patient management, antifungal usage and outcome and may be cost effective. Therefore, clinical validation studies in carefully selected at risk patient populations are urgently needed. Based on currently available data, it is most likely that molecular methods with be combined with other biomarkers such antigen detection tests to achieve optimal performance.

Molecular methods as well as Maldi-tof MS technology play an increasingly important role in the identification of fungi. It is clear that molecular identification strategies render more accurate identifications of fungal isolates than strategies based on morphology alone. However the relevance of identifying an unknown isolated to the smallest taxonomic unit 
should be evaluated in the clinical context. Furthermore, it remains essential to maintain morphological expertise to be able to validate the results of molecular tests. 


\section{Figures}

Figure 1

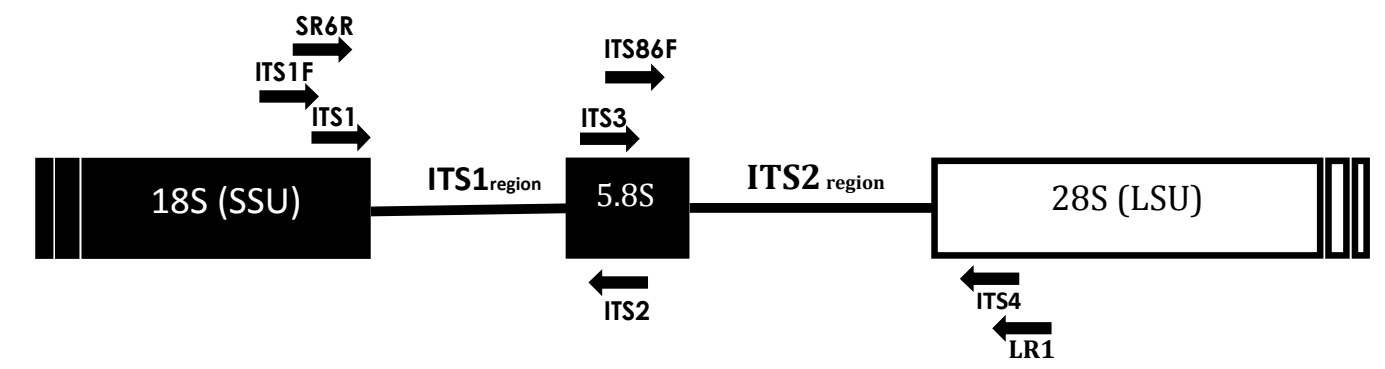

Figure 1. Schematic representation of the rDNA gene complex of the fungal genome with the most frequently used ITS-targeted primers (arrows). SSU: small subunit; LSU: large subunit. 
Figure 2

\begin{tabular}{|l|l|l|}
\hline Primer name & Sequence (5'-3') & Reference \\
\hline ITS1 (f) & TCCGTAGGTGAACCTGCGG & White et al. 1990 \\
\hline ITS1F (f) & CTTGGTCATTTAGAGGAAGTAA & Gardes et Bruns 1993 \\
\hline ITS2 (r) & GCTGCGTTCTTCATCGATGC & White et al. 1990 \\
\hline ITS3 (f) & GCATCGATGAAGAACGCAGC & White et al. 1990 \\
\hline ITS4 (r) & TCCTCCGCTTATTGATATGC & White et al. 1990 \\
\hline ITS86F (f) & GTGAATCATCGAATCTTTGAA & Turenne et al. 1999 \\
\hline SR6R (f) & AAGTAAAAGTCGTAACAAGG & Gräser et al. 1999 \\
\hline LR1 (r) & GGTTGGTTTCTTTTCCT & Gräser et al. 1999 \\
\hline
\end{tabular}

Figure 2. List of the most currently used primers targeting the ITS region of the fungal rDNA genes complex. (f) forward, (r)reverse 


\section{REFERENCES}

1. Burzykowski T, Molenberghs G, Abeck D, Haneke E, Hay R, Katsambas A, Roseeuw D, van de Kerkhof P, van Aelst R, Marynissen G. 2003. High prevalence of foot diseases in Europe: results of the Achilles Project. Mycoses 46:496-505.

2. Ghannoum MA, Hajjeh RA, Scher R, Konnikov N, Gupta AK, Summerbell R, Sullivan S, Daniel R, Krusinski P, Fleckman P, Rich P, Odom R, Aly R, Pariser D, Zaiac M, Rebell G, Lesher J, Gerlach B, Ponce-De-Leon GF, Ghannoum A, Warner J, Isham N, Elewski B. 2000. A large-scale North American study of fungal isolates from nails: the frequency of onychomycosis, fungal distribution, and antifungal susceptibility patterns. J Am Acad Dermatol 43:641-648.

3. Bitar D, Lortholary O, Le Strat Y, Nicolau J, Coignard B, Tattevin P, Che D, Dromer F. 2014. Population-based analysis of invasive fungal infections, france, 2001-2010. Emerg Infect Dis 20:1163-1169.

4. Tchernev G, Penev PK, Nenoff P, Zisova LG, Cardoso JC, Taneva T, Ginter-Hanselmayer G, Ananiev J, Gulubova M, Hristova R, Nocheva D, Guarneri C, Martino G, Kanazawa N. 2013. Onychomycosis: modern diagnostic and treatment approaches. Wien Med Wochenschr 163:1-12.

5. Cornely OA, Arikan-Akdagli S, Dannaoui E, Groll AH, Lagrou K, Chakrabarti A, Lanternier F, Pagano L, Skiada A, Akova M, Arendrup MC, Boekhout T, Chowdhary A, Cuenca-Estrella M, Freiberger T, Guinea J, Guarro J, de Hoog S, Hope W, Johnson E, Kathuria S, Lackner M, Lass-Flörl C, Lortholary O, Meis JF, Meletiadis J, Muñoz P, Richardson M, Roilides E, Tortorano AM, Ullmann AJ, van Diepeningen A, Verweij P, Petrikkos G. 2014. ESCMID and ECMM joint clinical guidelines for the diagnosis and management of mucormycosis 2013. Clin Microbiol Infect 20 Suppl 3:5-26.

6. Bustin SA, Benes V, Garson JA, Hellemans J, Huggett J, Kubista M, Mueller R, Nolan T, PfaffI MW, Shipley GL, Vandesompele J, Wittwer CT. 2009. The MIQE guidelines: minimum information for publication of quantitative real-time PCR experiments. Clin Chem 55:611622.

7. J L, O K. 2011. Diagnostic utility of DNA from Aspergillus in whole blood specimens. Current Fungal Infection Report 5:179-185.

8. Mrazek C L-FL. 2011. A Review of Biopsy Procedures for Molecular Tissue Diagnosis of Invasive Fungal Infections, p. 504-509, vol. 13. Current Infectious Disease Reports.

9. Imhof A, Schaer C, Schoedon G, Schaer DJ, Walter RB, Schaffner A, Schneemann M. 2003. Rapid detection of pathogenic fungi from clinical specimens using LightCycler real-time fluorescence PCR. Eur J Clin Microbiol Infect Dis 22:558-560.

10. Sakai K, Trabasso P, Moretti ML, Mikami Y, Kamei K, Gonoi T. 2014. Identification of fungal pathogens by visible microarray system in combination with isothermal gene amplification. Mycopathologia 178:11-26.

11. Park C, Kwon EY, Shin NY, Choi SM, Kim SH, Park SH, Lee DG, Choi JH, Yoo JH. 2011. Evaluation of nucleic acid sequence based amplification using fluorescence resonance energy transfer (FRET-NASBA) in quantitative detection of Aspergillus 18S rRNA. Med Mycol 49:7379.

12. Zhao Y, Park S, Kreiswirth BN, Ginocchio CC, Veyret R, Laayoun A, Troesch A, Perlin DS. 2009. Rapid real-time nucleic Acid sequence-based amplification-molecular beacon platform to detect fungal and bacterial bloodstream infections. J Clin Microbiol 47:2067-2078.

13. Alanio A, Bretagne S. 2014. Difficulties with molecular diagnostic tests for mould and yeast infections: where do we stand? Clin Microbiol Infect 20 Suppl 6:36-41.

14. B W, G H. 2013. State-of-the art procedures and quality management in diagnostic medical mycology. Current Fungal Infection Report 7:260-272.

15. Xhaard A, Lanternier F, Porcher R, Dannaoui E, Bergeron A, Clement L, Lacroix C, Herbrecht R, Legrand F, Mohty M, Michallet M, Cordonnier C, Malak S, Guyotat D, Couderc L, Socié G, 
Milpied N, Lortholary O, Ribaud P. 2012. Mucormycosis after allogeneic haematopoietic stem cell transplantation: a French Multicentre Cohort Study (2003-2008). Clin Microbiol Infect 18:E396-400.

16. Saegeman V, Maertens J, Meersseman W, Spriet I, Verbeken E, Lagrou K. 2010. Increasing incidence of mucormycosis in University Hospital, Belgium. Emerg Infect Dis 16:1456-1458.

17. Schoch CL, Seifert KA, Huhndorf S, Robert V, Spouge JL, Levesque CA, Chen W, Consortium FB, List FBCA. 2012. Nuclear ribosomal internal transcribed spacer (ITS) region as a universal DNA barcode marker for Fungi. Proc Natl Acad Sci U S A 109:6241-6246.

18. Buitrago MJ, Bernal-Martinez L, Castelli MV, Rodriguez-Tudela JL, Cuenca-Estrella M. 2014. Performance of panfungal--and specific-PCR-based procedures for etiological diagnosis of invasive fungal diseases on tissue biopsy specimens with proven infection: a 7-year retrospective analysis from a reference laboratory. J Clin Microbiol 52:1737-1740.

19. Babouee B, Goldenberger D, Elzi L, Lardinois D, Sadowski-Cron C, Bubendorf L, Savic Prince S, Battegay M, Frei R, Weisser M. 2013. Prospective study of a panfungal PCR assay followed by sequencing, for the detection of fungal DNA in normally sterile specimens in a clinical setting: a complementary tool in the diagnosis of invasive fungal disease? Clin Microbiol Infect 19:E354-357.

20. Sugawara Y, Nakase K, Nakamura A, Ohishi K, Sugimoto Y, Fujieda A, Monma F, Suzuki K, Masuya M, Matsushima Y, Wada H, Nobori T, Katayama N. 2013. Clinical utility of a panfungal polymerase chain reaction assay for invasive fungal diseases in patients with haematologic disorders. Eur J Haematol 90:331-339.

21. Landlinger C, Preuner S, Bašková L, van Grotel M, Hartwig NG, Dworzak M, Mann G, Attarbaschi A, Kager L, Peters C, Matthes-Martin S, Lawitschka A, van den Heuvel-Eibrink MM, Lion T. 2010. Diagnosis of invasive fungal infections by a real-time panfungal PCR assay in immunocompromised pediatric patients. Leukemia 24:2032-2038.

22. Marcos JY, Pincus DH. 2013. Fungal diagnostics: review of commercially available methods. Methods Mol Biol 968:25-54.

23. White PL, Hibbitts SJ, Perry MD, Green J, Stirling E, Woodford L, McNay G, Stevenson R, Barnes RA. 2014. Evaluation of a commercially developed semi-automated PCR-SERS assay for the diagnosis of invasive fungal disease. J Clin Microbiol.

24. Arendrup MC, Sulim S, Holm A, Nielsen L, Nielsen SD, Knudsen JD, Drenck NE, Christensen JJ, Johansen HK. 2011. Diagnostic issues, clinical characteristics, and outcomes for patients with fungemia. J Clin Microbiol 49:3300-3308.

25. Avni T, Leibovici L, Paul M. 2011. PCR diagnosis of invasive candidiasis: systematic review and meta-analysis. J Clin Microbiol 49:665-670.

26. Berenguer J, Buck M, Witebsky F, Stock F, Pizzo PA, Walsh TJ. 1993. Lysis-centrifugation blood cultures in the detection of tissue-proven invasive candidiasis. Disseminated versus single-organ infection. Diagn Microbiol Infect Dis 17:103-109.

27. Stone NR, Gorton RL, Barker K, Ramnarain P, Kibbler CC. 2013. Evaluation of PNA-FISH yeast traffic light for rapid identification of yeast directly from positive blood cultures and assessment of clinical impact. J Clin Microbiol 51:1301-1302.

28. Clancy CJ, Nguyen MH. 2013. Finding the "missing 50\%" of invasive candidiasis: how nonculture diagnostics will improve understanding of disease spectrum and transform patient care. Clin Infect Dis 56:1284-1292.

29. Cuenca-Estrella M, Verweij PE, Arendrup MC, Arikan-Akdagli S, Bille J, Donnelly JP, Jensen HE, Lass-Flörl C, Richardson MD, Akova M, Bassetti M, Calandra T, Castagnola E, Cornely OA, Garbino J, Groll AH, Herbrecht R, Hope WW, Kullberg BJ, Lortholary O, Meersseman W, Petrikkos G, Roilides E, Viscoli C, Ullmann AJ, Group EFIS. 2012. ESCMID* guideline for the diagnosis and management of Candida diseases 2012: diagnostic procedures. Clin Microbiol Infect 18 Suppl 7:9-18.

30. Khot PD, Fredricks DN. 2009. PCR-based diagnosis of human fungal infections. Expert Rev Anti Infect Ther 7:1201-1221. 
31. Kasai M, Francesconi A, Petraitiene R, Petraitis V, Kelaher AM, Kim HS, Meletiadis J, Sein T, Bacher J, Walsh TJ. 2006. Use of quantitative real-time PCR to study the kinetics of extracellular DNA released from Candida albicans, with implications for diagnosis of invasive Candidiasis. J Clin Microbiol 44:143-150.

32. Nguyen MH, Wissel MC, Shields RK, Salomoni MA, Hao B, Press EG, Shields RM, Cheng S, Mitsani D, Vadnerkar A, Silveira FP, Kleiboeker SB, Clancy CJ. 2012. Performance of Candida real-time polymerase chain reaction, $\beta$-D-glucan assay, and blood cultures in the diagnosis of invasive candidiasis. Clin Infect Dis 54:1240-1248.

33. De Pauw B, Walsh TJ, Donnelly JP, Stevens DA, Edwards JE, Calandra T, Pappas PG, Maertens J, Lortholary O, Kauffman CA, Denning DW, Patterson TF, Maschmeyer G, Bille J, Dismukes WE, Herbrecht R, Hope WW, Kibbler CC, Kullberg BJ, Marr KA, Muñoz P, Odds FC, Perfect JR, Restrepo A, Ruhnke M, Segal BH, Sobel JD, Sorrell TC, Viscoli C, Wingard JR, Zaoutis T, Bennett JE, Group EOfRaToCIFIC, Group NIOAaIDMSGEMC. 2008. Revised definitions of invasive fungal disease from the European Organization for Research and Treatment of Cancer/Invasive Fungal Infections Cooperative Group and the National Institute of Allergy and Infectious Diseases Mycoses Study Group (EORTC/MSG) Consensus Group. Clin Infect Dis 46:1813-1821.

34. D'Haese J, Theunissen K, Vermeulen E, Schoemans H, De Vlieger G, Lammertijn L, Meersseman P, Meersseman W, Lagrou K, Maertens J. 2012. Detection of galactomannan in bronchoalveolar lavage fluid samples of patients at risk for invasive pulmonary aspergillosis: analytical and clinical validity. J Clin Microbiol 50:1258-1263.

35. Zou M, Tang L, Zhao S, Zhao Z, Chen L, Chen P, Huang Z, Li J, Fan X. 2012. Systematic review and meta-analysis of detecting galactomannan in bronchoalveolar lavage fluid for diagnosing invasive aspergillosis. PLoS One 7:e43347.

36. White PL, Barton R, Guiver M, Linton CJ, Wilson S, Smith M, Gomez BL, Carr MJ, Kimmitt PT, Seaton S, Rajakumar K, Holyoake T, Kibbler CC, Johnson E, Hobson RP, Jones B, Barnes RA. 2006. A consensus on fungal polymerase chain reaction diagnosis?: a United KingdomIreland evaluation of polymerase chain reaction methods for detection of systemic fungal infections. J Mol Diagn 8:376-384.

37. White PL, Perry MD, Loeffler J, Melchers W, Klingspor L, Bretagne S, McCulloch E, CuencaEstrella M, Finnstrom N, Donnelly JP, Barnes RA, Initiative EAP. 2010. Critical stages of extracting DNA from Aspergillus fumigatus in whole-blood specimens. J Clin Microbiol 48:3753-3755.

38. Springer J, Morton CO, Perry M, Heinz WJ, Paholcsek M, Alzheimer M, Rogers TR, Barnes RA, Einsele H, Loeffler J, White PL. 2013. Multicenter comparison of serum and whole-blood specimens for detection of Aspergillus DNA in high-risk hematological patients. J Clin Microbiol 51:1445-1450.

39. Rickerts V, Mousset S, Lambrecht E, Tintelnot K, Schwerdtfeger R, Presterl E, Jacobi V, JustNubling G, Bialek R. 2007. Comparison of histopathological analysis, culture, and polymerase chain reaction assays to detect invasive mold infections from biopsy specimens. Clin Infect Dis 44:1078-1083.

40. Torelli R, Sanguinetti M, Moody A, Pagano L, Caira M, De Carolis E, Fuso L, De Pascale G, Bello G, Antonelli M, Fadda G, Posteraro B. 2011. Diagnosis of invasive aspergillosis by a commercial real-time PCR assay for Aspergillus DNA in bronchoalveolar lavage fluid samples from high-risk patients compared to a galactomannan enzyme immunoassay. J Clin Microbiol 49:4273-4278.

41. Guinea J, Padilla C, Escribano P, Muñoz P, Padilla B, Gijón P, Bouza E. 2013. Evaluation of MycAssay ${ }^{\mathrm{TM}}$ Aspergillus for diagnosis of invasive pulmonary aspergillosis in patients without hematological cancer. PLoS One 8:e61545.

42. Lu Y, Ling G, Qiang C, Ming Q, Wu C, Wang K, Ying Z. 2011. PCR diagnosis of Pneumocystis pneumonia: a bivariate meta-analysis. J Clin Microbiol 49:4361-4363. 
43. Fan LC, Lu HW, Cheng KB, Li HP, Xu JF. 2013. Evaluation of PCR in bronchoalveolar lavage fluid for diagnosis of Pneumocystis jirovecii pneumonia: a bivariate meta-analysis and systematic review. PLoS One 8:e73099.

44. Hauser PM, Bille J, Lass-Florl C, Geltner C, Feldmesser M, Levi M, Patel H, Muggia V, Alexander B, Hughes M, Follett SA, Cui X, Leung F, Morgan G, Moody A, Perlin DS, Denning DW. 2011. Multicenter, prospective clinical evaluation of respiratory samples from subjects at risk for Pneumocystis jirovecii infection by use of a commercial real-time PCR assay. J Clin Microbiol 49:1872-1878.

45. Morris A, Norris KA. 2012. Colonization by Pneumocystis jirovecii and its role in disease. Clin Microbiol Rev 25:297-317.

46. Botterel F, Cabaret O, Foulet F, Cordonnier C, Costa JM, Bretagne S. 2012. Clinical significance of quantifying Pneumocystis jirovecii DNA by using real-time PCR in bronchoalveolar lavage fluid from immunocompromised patients. J Clin Microbiol 50:227231.

47. Damiani C, Le Gal S, Da Costa C, Virmaux M, Nevez G, Totet A. 2013. Combined quantification of pulmonary Pneumocystis jirovecii DNA and serum (1->3)- $\beta$-D-glucan for differential diagnosis of pneumocystis pneumonia and Pneumocystis colonization. J Clin Microbiol 51:3380-3388.

48. Costa JM, Botterel F, Cabaret O, Foulet F, Cordonnier C, Bretagne S. 2012. Association between circulating DNA, serum (1->3)- $\beta$-D-glucan, and pulmonary fungal burden in Pneumocystis pneumonia. Clin Infect Dis 55:e5-8.

49. Mahmud A, Lee R, Munfus-McCray D, Kwiatkowski N, Subramanian A, Neofytos D, Carroll K, Zhang SX. 2012. Actinomucor elegans as an emerging cause of Mucormycosis. J Clin Microbiol 50:1092-1095.

50. N L, JL C, F B, M M, MP H. 2014. Mortierella wolfii-associated invasive disease., p. 1591, vol. 20. Emergence Infectious Disease.

51. Gupta AK, Ryder JE, Chow M, Cooper EA. 2005. Dermatophytosis: the management of fungal infections. Skinmed 4:305-310.

52. Wang W, Xi H, Huang M, Wang J, Fan M, Chen Y, Shao H, Li X. 2014. Performance of mass spectrometric identification of bacteria and yeasts routinely isolated in a clinical microbiology laboratory using MALDI-TOF MS. J Thorac Dis 6:524-533.

53. Steensels D, Verhaegen J, Lagrou K. 2011. Matrix-assisted laser desorption ionization-time of flight mass spectrometry for the identification of bacteria and yeasts in a clinical microbiological laboratory: a review. Acta Clin Belg 66:267-273.

54. Bille E, Dauphin B, Leto J, Bougnoux ME, Beretti JL, Lotz A, Suarez S, Meyer J, Join-Lambert O, Descamps P, Grall N, Mory F, Dubreuil L, Berche P, Nassif X, Ferroni A. 2012. MALDI-TOF MS Andromas strategy for the routine identification of bacteria, mycobacteria, yeasts, Aspergillus spp. and positive blood cultures. Clin Microbiol Infect 18:1117-1125.

55. Hamprecht A, Christ S, Oestreicher T, Plum G, Kempf VA, Göttig S. 2014. Performance of two MALDI-TOF MS systems for the identification of yeasts isolated from bloodstream infections and cerebrospinal fluids using a time-saving direct transfer protocol. Med Microbiol Immunol 203:93-99.

56. Bader 0. 2013. MALDI-TOF-MS-based species identification and typing approaches in medical mycology. Proteomics 13:788-799.

57. Bader O, Weig M, Taverne-Ghadwal L, Lugert R, Gross U, Kuhns M. 2011. Improved clinical laboratory identification of human pathogenic yeasts by matrix-assisted laser desorption ionization time-of-flight mass spectrometry. Clin Microbiol Infect 17:1359-1365.

58. Marklein G, Josten M, Klanke U, Muller E, Horre R, Maier T, Wenzel T, Kostrzewa M, Bierbaum G, Hoerauf A, Sahl HG. 2009. Matrix-assisted laser desorption ionization-time of flight mass spectrometry for fast and reliable identification of clinical yeast isolates. J Clin Microbiol 47:2912-2917. 
59. Pence MA, McElvania Tekippe E, Wallace MA, Burnham CA. 2014. Comparison and optimization of two MALDI-TOF MS platforms for the identification of medically relevant yeast species. Eur J Clin Microbiol Infect Dis.

60. Cassagne C, Ranque S, Normand AC, Fourquet P, Thiebault S, Planard C, Hendrickx M, Piarroux R. 2011. Mould routine identification in the clinical laboratory by matrix-assisted laser desorption ionization time-of-flight mass spectrometry. PLoS One 6:e28425.

61. Vlek A, Kolecka A, Khayhan K, Theelen B, Groenewald M, Boel E, Boekhout T, Group MS. 2014. Interlaboratory comparison of sample preparation methods, database expansions, and cutoff values for identification of yeasts by matrix-assisted laser desorption ionization-time of flight mass spectrometry using a yeast test panel. J Clin Microbiol 52:3023-3029.

62. Schulthess B, Bloemberg GV, Zbinden R, Böttger EC, Hombach M. 2014. Evaluation of the Bruker MALDI Biotyper for identification of Gram-positive rods: development of a diagnostic algorithm for the clinical laboratory. J Clin Microbiol 52:1089-1097.

63. Ranque S, Normand AC, Cassagne C, Murat JB, Bourgeois N, Dalle F, Gari-Toussaint M, Fourquet $P$, Hendrickx M, Piarroux R. 2014. MALDI-TOF mass spectrometry identification of filamentous fungi in the clinical laboratory. Mycoses 57:135-140.

64. Coulibaly O, Marinach-Patrice C, Cassagne C, Piarroux R, Mazier D, Ranque S. 2011. Pseudallescheria/Scedosporium complex species identification by Matrix-Assisted Laser Desorption lonization Time-Of-Flight Mass Spectrometry. Med Mycol 49:621-626.

65. L'Ollivier C, Cassagne C, Normand AC, Bouchara JP, Contet-Audonneau N, Hendrickx M, Fourquet P, Coulibaly O, Piarroux R, Ranque S. 2013. A MALDI-TOF MS procedure for clinical dermatophyte species identification in the routine laboratory. Med Mycol 51:713-720.

66. Normand AC, Cassagne C, Ranque S, L'ollivier C, Fourquet P, Roesems S, Hendrickx M, Piarroux R. 2013. Assessment of various parameters to improve MALDI-TOF MS reference spectra libraries constructed for the routine identification of filamentous fungi. BMC Microbiol 13:76.

67. de Respinis S, Tonolla M, Pranghofer S, Petrini L, Petrini O, Bosshard PP. 2013. Identification of dermatophytes by matrix-assisted laser desorption/ionization time-of-flight mass spectrometry. Med Mycol 51:514-521.

68. Pounder JI, Williams S, Hansen D, Healy M, Reece K, Woods GL. 2005. Repetitive-sequencePCR-based DNA fingerprinting using the Diversilab system for identification of commonly encountered dermatophytes. J Clin Microbiol 43:2141-2147.

69. Müller FM, Werner KE, Kasai M, Francesconi A, Chanock SJ, Walsh TJ. 1998. Rapid extraction of genomic DNA from medically important yeasts and filamentous fungi by highspeed cell disruption. J Clin Microbiol 36:1625-1629.

70. van Burik JA, Schreckhise RW, White TC, Bowden RA, Myerson D. 1998. Comparison of six extraction techniques for isolation of DNA from filamentous fungi. Med Mycol 36:299-303.

71. Pryce TM, Palladino S, Kay ID, Coombs GW. 2003. Rapid identification of fungi by sequencing the ITS1 and ITS2 regions using an automated capillary electrophoresis system. Med Mycol 41:369-381.

72. Castanheira M, Woosley LN, Diekema DJ, Jones RN, Pfaller MA. 2013. Candida guilliermondii and other species of candida misidentified as Candida famata: assessment by vitek 2, DNA sequencing analysis, and matrix-assisted laser desorption ionization-time of flight mass spectrometry in two global antifungal surveillance programs. J Clin Microbiol 51:117-124.

73. Nawrot U, Wlodarczyk K, Wrobel M, Wasik A, Dobosz T. 2010. Comparison of the utility of five commercial kits for extraction of DNA from Aspergillus fumigatus spores. Acta Biochim Pol 57:567-571.

74. Liu D, Coloe S, Baird R, Pederson J. 2000. Rapid mini-preparation of fungal DNA for PCR. J Clin Microbiol 38:471.

75. Romanelli AM, Fu J, Herrera ML, Wickes BL. 2014. A universal DNA extraction and PCR amplification method for fungal rDNA sequence-based identification. Mycoses. 
76. Borman AM, Linton CJ, Miles SJ, Campbell CK, Johnson EM. 2006. Ultra-rapid preparation of total genomic DNA from isolates of yeast and mould using Whatman FTA filter paper technology - a reusable DNA archiving system. Med Mycol 44:389-398.

77. Borman AM, Linton CJ, Miles SJ, Johnson EM. 2008. Molecular identification of pathogenic fungi. J Antimicrob Chemother 61 Suppl 1:i7-12.

78. Borman AM, Fraser M, Linton CJ, Palmer MD, Johnson EM. 2010. An improved protocol for the preparation of total genomic DNA from isolates of yeast and mould using Whatman FTA filter papers. Mycopathologia 169:445-449.

79. Zhong KJ, Salas CJ, Shafer R, Gubanov A, Gasser RA, Magill AJ, Forney JR, Kain KC. 2001. Comparison of IsoCode STIX and FTA Gene Guard collection matrices as whole-blood storage and processing devices for diagnosis of malaria by PCR. J Clin Microbiol 39:1195-1196.

80. Li CC, Beck IA, Seidel KD, Frenkel LM. 2004. Persistence of human immunodeficiency virus type 1 subtype B DNA in dried-blood samples on FTA filter paper. J Clin Microbiol 42:38473849.

81. Seifert KA. 2009. Progress towards DNA barcoding of fungi. Mol Ecol Resour 9 Suppl s1:8389.

82. Institute WPCdM-ACaLS. Clinical and Laboratory Standards Institute. 2008. Interpretive criteria for identification of bacteria and fungy by DNA target sequencing: guideline.

83. Balajee SA, Borman AM, Brandt ME, Cano J, Cuenca-Estrella M, Dannaoui E, Guarro J, Haase G, Kibbler CC, Meyer W, O'Donnell K, Petti CA, Rodriguez-Tudela JL, Sutton D, Velegraki A, Wickes BL. 2009. Sequence-based identification of Aspergillus, fusarium, and mucorales species in the clinical mycology laboratory: where are we and where should we go from here? J Clin Microbiol 47:877-884.

84. Iwen PC, Hinrichs SH, Rupp ME. 2002. Utilization of the internal transcribed spacer regions as molecular targets to detect and identify human fungal pathogens. Med Mycol 40:87-109.

85. Wang X, Fu YF, Wang RY, Li L, Cao YH, Chen YQ, Zhao HZ, Zhang QQ, Wu JQ, Weng XH, Cheng XJ, Zhu LP. 2014. Identification of clinically relevant fungi and prototheca species by rRNA gene sequencing and multilocus PCR coupled with electrospray ionization mass spectrometry. PLoS One 9:e98110.

86. Op De Beeck M, Lievens B, Busschaert P, Declerck S, Vangronsveld J, Colpaert JV. 2014. Comparison and validation of some ITS primer pairs useful for fungal metabarcoding studies. PLoS One 9:e97629.

87. BL K-CKaW. The conversion from classical studies in fungal pathogenesis to the molecular era. Molecular principles of fungal pathogenesis ed. J. Heitmanet et al. ASM Press, Washington DC.

88. White TJ BT, Lee SB, Taylor JW. Amplificatin and direct sequencing of fungal ribosomal RNA genes for phylogenetics., p. 315-322. In Innis MA, Gelfand DH, Sninsky JJ, White TJ. PCR protocols: a guide to methods and applications., United States Academic Press, San Diego, 1990.

89. Gardes M, Bruns TD. 1993. ITS primers with enhanced specificity for basidiomycetes-application to the identification of mycorrhizae and rusts. Mol Ecol 2:113-118.

90. Dannaoui E, Paugam A, Develoux M, Chochillon C, Matheron J, Datry A, Bouges-Michel C, Bonnal C, Dromer F, Bretagne S. 2010. Comparison of antifungal MICs for yeasts obtained using the EUCAST method in a reference laboratory and the Etest in nine different hospital laboratories. Clin Microbiol Infect 16:863-869.

91. Schwarz P, Bretagne S, Gantier JC, Garcia-Hermoso D, Lortholary O, Dromer F, Dannaoui E. 2006. Molecular identification of zygomycetes from culture and experimentally infected tissues. J Clin Microbiol 44:340-349.

92. Vancov T, Keen B. 2009. Amplification of soil fungal community DNA using the ITS86F and ITS4 primers. FEMS Microbiol Lett 296:91-96. 
93. Turenne CY, Sanche SE, Hoban DJ, Karlowsky JA, Kabani AM. 1999. Rapid identification of fungi by using the ITS2 genetic region and an automated fluorescent capillary electrophoresis system. J Clin Microbiol 37:1846-1851.

94. Kami M, Fukui T, Ogawa S, Kazuyama Y, Machida U, Tanaka Y, Kanda Y, Kashima T, Yamazaki Y, Hamaki T, Mori S, Akiyama H, Mutou Y, Sakamaki H, Osumi K, Kimura S, Hirai H. 2001. Use of real-time PCR on blood samples for diagnosis of invasive aspergillosis. Clin Infect Dis 33:1504-1512.

95. Lott TJ, Burns BM, Zancope-Oliveira R, Elie CM, Reiss E. 1998. Sequence analysis of the internal transcribed spacer 2 (ITS2) from yeast species within the genus Candida. Curr Microbiol 36:63-69.

96. Ferrer C, Colom F, Frasés S, Mulet E, Abad JL, Alió JL. 2001. Detection and identification of fungal pathogens by PCR and by ITS2 and 5.8S ribosomal DNA typing in ocular infections. J Clin Microbiol 39:2873-2879.

97. Ge YP, Wang L, Lu GX, Shen YN, Liu WD. 2012. A simple and reliable PCR-restriction fragment length polymorphism assay to identify Candida albicans and its closely related Candida dubliniensis. Braz J Microbiol 43:873-879.

98. DL C. 2013. Principles of Capillary-Based Sequencing for Clinical Microbiologists, vol. 35. Clinical Microbiology Newsletter.

99. Trama JP, Mordechai E, Adelson ME. 2005. Detection and identification of Candida species associated with Candida vaginitis by real-time PCR and pyrosequencing. Mol Cell Probes 19:145-152.

100. Pannanusorn S, Elings MA, Römling U, Fernandez V. 2012. Pyrosequencing of a hypervariable region in the internal transcribed spacer 2 to identify clinical yeast isolates. Mycoses 55:172-180.

101. Trama JP, Mordechai E, Adelson ME. 2005. Detection of Aspergillus fumigatus and a mutation that confers reduced susceptibility to itraconazole and posaconazole by real-time PCR and pyrosequencing. J Clin Microbiol 43:906-908.

102. Souza AC, Ferreira RC, Gonçalves SS, Quindós G, Eraso E, Bizerra FC, Briones MR, Colombo AL. 2012. Accurate identification of Candida parapsilosis (sensu lato) by use of mitochondrial DNA and real-time PCR. J Clin Microbiol 50:2310-2314.

103. McTaggart L, Richardson SE, Seah C, Hoang L, Fothergill A, Zhang SX. 2011. Rapid identification of Cryptococcus neoformans var. grubii, C. neoformans var. neoformans, and C. gattii by use of rapid biochemical tests, differential media, and DNA sequencing. J Clin Microbiol 49:2522-2527.

104. Balajee SA, Sigler L, Brandt ME. 2007. DNA and the classical way: identification of medically important molds in the 21st century. Med Mycol 45:475-490.

105. Oechsler RA, Feilmeier MR, Ledee DR, Miller D, Diaz MR, Fini ME, Fell JW, Alfonso EC. 2009. Utility of molecular sequence analysis of the ITS rRNA region for identification of Fusarium spp. from ocular sources. Invest Ophthalmol Vis Sci 50:2230-2236.

106. Dubey SC, Priyanka K, Singh V. 2014. Phylogenetic relationship between different race representative populations of Fusarium oxysporum $\mathrm{f}$. sp. ciceris in respect of translation elongation factor- $1 \alpha, \beta$-tubulin, and internal transcribed spacer region genes. Arch Microbiol 196:445-452.

107. Tortorano AM, Prigitano A, Esposto MC, Arsic Arsenijevic V, Kolarovic J, Ivanovic D, Paripovic L, Klingspor L, Nordøy I, Hamal P, Arikan Akdagli S, Ossi C, Grancini A, Cavanna C, Lo Cascio G, Scarparo C, Candoni A, Caira M, Drogari Apiranthitou M, Group EW. 2014. European Confederation of Medical Mycology (ECMM) epidemiological survey on invasive infections due to Fusarium species in Europe. Eur J Clin Microbiol Infect Dis 33:1623-1630.

108. Geiser DM dMJ-GM, Kang S, Makalowska I, Veeraraghavan N, Ward TJ, Zhang N, Kuldau GA and O'Donnell K. 2004. FUSARIUM-ID v. 1.0: a DNA sequence database for identifying Fusarium. European Journal of Plant Pathology 110: 473-479. 
109. Cafarchia C, latta R, Latrofa MS, Gräser Y, Otranto D. 2013. Molecular epidemiology, phylogeny and evolution of dermatophytes. Infect Genet Evol 20:336-351.

110. Verrier J, KrähenbühI L, Bontems O, Fratti M, Salamin K, Monod M. 2013. Dermatophyte identification in skin and hair samples using a simple and reliable nested polymerase chain reaction assay. $\mathrm{Br} J$ Dermatol 168:295-301.

111. Ninet B, Jan I, Bontems O, Léchenne B, Jousson O, Panizzon R, Lew D, Monod M. 2003. Identification of dermatophyte species by $28 \mathrm{~S}$ ribosomal DNA sequencing with a commercial kit. J Clin Microbiol 41:826-830.

112. Gräser Y, El Fari M, Vilgalys R, Kuijpers AF, De Hoog GS, Presber W, Tietz H. 1999. Phylogeny and taxonomy of the family Arthrodermataceae (dermatophytes) using sequence analysis of the ribosomal ITS region. Med Mycol 37:105-114.

113. Gräser Y, Scott J, Summerbell R. 2008. The new species concept in dermatophytes-a polyphasic approach. Mycopathologia 166:239-256.

114. Gräser Y, Czaika V, Ohst T. 2012. Diagnostic PCR of dermatophytes--an overview. J Dtsch Dermatol Ges 10:721-726.

115. Symoens F, Jousson O, Packeu A, Fratti M, Staib P, Mignon B, Monod M. 2013. The dermatophyte species Arthroderma benhamiae: intraspecies variability and mating behaviour. J Med Microbiol 62:377-385. 